\title{
QAGUPUBLICATIONS
}

Water Resources Research

Supporting Information for

\section{Multisite Daily Streamflow Simulation with Time Irreversibility}

Jeenu Mathai ${ }^{1}$ and P. P. Mujumdar ${ }^{1,2}$

${ }^{1}$ Department of Civil Engineering, Indian Institute of Science, Bangalore-560012, India

${ }^{2}$ Interdisciplinary Centre for Water Research, Indian Institute of Science, Bangalore-560012, India

Corresponding author: P. P. Mujumdar, pradeep@civil.iisc.ernet.in

\section{Content of this file:}

Table S1 
Table S1 (a). Parameters of flows at Tekra station, Godavari River Basin.

\begin{tabular}{|c|c|c|c|c|c|}
\hline \multirow[b]{2}{*}{ Month } & \multicolumn{2}{|c|}{ Ascension curve } & \multicolumn{2}{|c|}{ Recession curve } & \multirow{2}{*}{$\begin{array}{c}\text { Mean monthly } \\
\text { flow } \\
Q^{m^{3} / s}\end{array}$} \\
\hline & $\begin{array}{l}\text { Scale } \\
\quad a\end{array}$ & $\begin{array}{c}\text { Shape } \\
b\end{array}$ & $\begin{array}{c}\text { Upper } \\
\text { recession } \\
b_{1}\end{array}$ & $\begin{array}{c}\text { Lower } \\
\text { recession } \\
b_{2}\end{array}$ & \\
\hline October & 176.89 & 0.52 & 0.15 & 0.10 & 1123.14 \\
\hline November & 23.82 & 0.55 & 0.11 & 0.08 & 279.40 \\
\hline December & 9.97 & 0.57 & 0.06 & 0.04 & 129.10 \\
\hline January & 6.74 & 0.62 & 0.06 & 0.04 & 88.66 \\
\hline February & 6.88 & 0.54 & 0.06 & 0.05 & 81.14 \\
\hline March & 4.43 & 0.63 & 0.07 & 0.05 & 47.49 \\
\hline April & 2.63 & 0.65 & 0.08 & 0.05 & 26.87 \\
\hline May & 2.22 & 0.57 & 0.09 & 0.07 & 20.55 \\
\hline June & 51.14 & 0.36 & 0.25 & 0.14 & 475.79 \\
\hline July & 786.92 & 0.63 & 0.23 & 0.19 & 2724.54 \\
\hline August & 1530.23 & 0.73 & 0.24 & 0.17 & 5052.26 \\
\hline September & 717.11 & 0.65 & 0.22 & 0.12 & 3283.66 \\
\hline
\end{tabular}

Table S1 (b). Parameters of flows at Jagdalpur station, Godavari River Basin.

\begin{tabular}{|c|c|c|c|c|c|}
\hline \multirow[b]{2}{*}{ Month } & \multicolumn{2}{|c|}{ Ascension curve } & \multicolumn{2}{|c|}{ Recession curve } & \multirow[b]{2}{*}{$\begin{array}{l}\text { Mean monthly flow } \\
\qquad Q^{m^{3} / s}\end{array}$} \\
\hline & $\begin{array}{l}\text { Scale } \\
\quad a\end{array}$ & $\begin{array}{c}\text { Shape } \\
b\end{array}$ & $\begin{array}{c}\text { Upper } \\
\text { recession } \\
b_{1}\end{array}$ & $\begin{array}{c}\text { Lower } \\
\text { recession } \\
b_{2}\end{array}$ & \\
\hline October & 15.49 & 0.56 & 0.19 & 0.09 & 109.29 \\
\hline November & 3.17 & 0.57 & 0.10 & 0.05 & 39.44 \\
\hline December & 0.91 & 0.71 & 0.05 & 0.03 & 24.03 \\
\hline January & 0.78 & 0.66 & 0.04 & 0.03 & 17.65 \\
\hline February & 0.76 & 0.70 & 0.05 & 0.04 & 13.08 \\
\hline March & 0.71 & 0.68 & 0.06 & 0.04 & 11.29 \\
\hline April & 1.10 & 0.62 & 0.11 & 0.06 & 9.68 \\
\hline May & 2.04 & 0.53 & 0.17 & 0.10 & 13.00 \\
\hline June & 17.20 & 0.45 & 0.36 & 0.17 & 72.73 \\
\hline July & 98.64 & 0.63 & 0.32 & 0.20 & 270.85 \\
\hline August & 143.18 & 0.71 & 0.25 & 0.20 & 439.97 \\
\hline September & 85.22 & 0.66 & 0.23 & 0.14 & 303.25 \\
\hline
\end{tabular}

